\title{
Effects of carbohydrate supplementation on aerobic exercise performance during acute high altitude exposure and after 22 days of acclimatization and energy deficit
}

Karleigh E. Bradbury ${ }^{1}$, Claire E. Berryman ${ }^{2,3}$, Marques A. Wilson², Adam J. Luippold ${ }^{1}$, Robert W. Kenefick', Andrew J. Young ${ }^{2,3}$ and Stefan M. Pasiakos ${ }^{2^{*}}$ (i)

\begin{abstract}
Background: The ergogenic effects of supplemental carbohydrate on aerobic exercise performance at high altitude (HA) may be modulated by acclimatization status. Longitudinal evaluation of potential performance benefits of carbohydrate supplementation in the same volunteers before and after acclimatization to HA have not been reported.

Purpose: This study examined how consuming carbohydrate affected 2-mile time trial performance in lowlanders at HA (4300 m) before and after acclimatization.

Methods: Fourteen unacclimatized men performed 80 min of metabolically-matched $(\sim 1.7 \mathrm{~L} / \mathrm{min})$ treadmill walking at sea level (SL), after $\sim 5 \mathrm{~h}$ of acute HA exposure, and after 22 days of $\mathrm{HA}$ acclimatization and concomitant $40 \%$ energy deficit (chronic HA). Before, and every 20 min during walking, participants consumed either carbohydrate $(\mathrm{CHO}, n=8$; $65.25 \mathrm{~g}$ fructose $+79.75 \mathrm{~g}$ glucose, $1.8 \mathrm{~g}$ carbohydrate $/ \mathrm{min}$ ) or flavor-matched placebo (PLA, $n=6$ ) beverages. A selfpaced 2-mile treadmill time trial was performed immediately after completing the 80-min walk.

Results: There were no differences $(P>0.05)$ in time trial duration between $\mathrm{CHO}$ and PLA at SL, acute HA, or chronic HA. Time trial duration was longer $(P<0.05)$ at acute HA (mean $\pm S D ; 27.3 \pm 6.3$ min) compared to chronic HA ( $23.6 \pm 4.5 \mathrm{~min})$ and $\mathrm{SL}(17.6 \pm 3.6 \mathrm{~min})$; however, time trial duration at chronic HA was still longer than $\mathrm{SL}(P<0.05)$.
\end{abstract}

Conclusion: These data suggest that carbohydrate supplementation does not enhance aerobic exercise performance in lowlanders acutely exposed or acclimatized to HA.

Trial registration: NCT, NCT02731066, Registered March 292,016

Keywords: Hypoxia, Time trial, Ergogenic aid

\section{Background}

Reduced arterial oxygen content degrades aerobic exercise performance in lowlanders initially exposed to high altitude (HA) [1]. After several weeks of HA exposure, acclimatization occurs, and aerobic exercise performance partially improves [1-3]. Another factor that may impact the performance degradation seen at altitude are changes in substrate oxidation [4], as endogenous carbohydrate oxidation during exercise may be higher with acute HA

\footnotetext{
*Correspondence: Stefan.m.pasiakos.civ@mail.mil

${ }^{2}$ Military Nutrition Division, US Army Research Institute of Environmental

Medicine, 10 General Greene Avenue, Bldg, Natick, MA 42, USA

Full list of author information is available at the end of the article
}

exposure compared to absolute $\mathrm{VO}_{2}$-matched exercise at sea level (SL) [5]. After acclimatization, muscle glucose uptake during exercise is also increased relative to SL [6]. Collectively, these data suggest that consuming supplemental carbohydrate during exercise at HA might be an effective strategy to attenuate performance decrements by sparing endogenous carbohydrate stores and meeting the apparent increase in carbohydrate requirements during exercise.

Carbohydrate supplementation during exercise at SL spares endogenous carbohydrate stores and delays the onset of fatigue [7, 8]. Effects of carbohydrate supplementation on

(C) The Author(s). 2020 Open Access This article is distributed under the terms of the Creative Commons Attribution 4.0 International License (http://creativecommons.org/licenses/by/4.0/), which permits unrestricted use, distribution, and 
exercise performance at HA are not well described. In unacclimatized men, Fulco et al. [9] demonstrated that carbohydrate supplementation during exercise enhanced time trial performance compared to placebo after 3 days of HA (4300 $\mathrm{m}$ ) exposure concomitant with a 30\% energy deficit (negative energy balance is largely unavoidable and commonly experienced by lowlanders sojourning at HA) [10]. However, carbohydrate supplementation had no further performance benefit after 10 days of acclimatization and negative energy balance. In a follow-up study, Fulco et al. [11] found no benefit of carbohydrate supplementation on time trial performance on the first and third day of HA exposure in previously HA acclimatized men in a state of energy balance. These discordant results from vastly different experimental designs (i.e., energy and acclimatization status of participants) suggest that the potential ergogenic effects of supplemental carbohydrate on exercise performance at HA may, in part, be modulated by acclimatization. To extend these findings $[9,11]$, we examined the effects of carbohydrate supplementation on aerobic exercise performance in unacclimatized men after $5 \mathrm{~h}$ of HA ( $4300 \mathrm{~m})$ exposure and following 22 days of HA acclimatization and concomitant $40 \%$ energy deficit. Based on the studies by Fulco and colleagues $[9,11]$, we hypothesized that carbohydrate supplementation would enhance exercise performance during acute HA exposure, but not after HA acclimatization.

\section{Methods}

\section{Experimental design}

Data included in this Short Report were secondary analyses from a controlled feeding and exercise study that assessed the effects of high protein diets on body composition during sustained energy deficit at HA [12]. This study (clinical trials.gov: NCT02731066) was approved by the Institutional Review Board at the US Army Research Institute of Environmental Medicine (USARIEM, Natick, MA) and participants provided written informed consent. Characteristics of the 14 unacclimatized, young men included in this report were detailed by Young et al. [13].

The experimental design has been reported extensively [12-16]. In brief, the study was conducted over 43 consecutive days. During the first 21 days (SL), participants consumed a self-selected, weight-maintaining diet, maintained habitual exercise levels, and were free-living but visited the laboratory daily. On SL day 21, participants were flown from Boston, MA to Denver, CO where they were placed on supplemental oxygen until being driven to the summit of Pikes Peak, CO $(4300 \mathrm{~m})$ the following morning where they resided at the USARIEM Maher Memorial Altitude Laboratory for the next 22 days at HA. During HA, participants were under constant supervision, performed daily exercise, and consumed either standard protein (mean $\pm \mathrm{SD} ; 1.1 \pm 0.2 \mathrm{~g} / \mathrm{kg} / \mathrm{d}$ ) or high protein $(2.1 \pm 0.2 \mathrm{~g} / \mathrm{kg} / \mathrm{d})$, carbohydrate-matched, energy deficient diets (40\%; 30\% by energy restriction and $10 \%$ by exercise). Fat was the primary manipulated macronutrient during the energy deficit, such that the standard protein group consumed $1.1 \pm 0.2 \mathrm{~g} / \mathrm{kg} / \mathrm{d}$ fat, and the high protein group consumed $0.7 \pm 0.1 \mathrm{~g} / \mathrm{kg} / \mathrm{d}$ fat [12]. The diet intervention resulted in a $7.9 \pm 1.9 \mathrm{~kg}$ loss of total body mass [13].

\section{Exercise and 2-mile time trial}

Participants were randomized to groups and were provided equal volumes of flavor-matched carbohydrate (CHO; $65.25 \mathrm{~g}$ fructose $+79.75 \mathrm{~g}$ glucose ingested at 1.8 $\mathrm{g} / \mathrm{min}, n=8,3$ standard and 5 high protein) and placebo (PLA; $n=6,4$ standard and 2 high protein) beverages during $80 \mathrm{~min}$ of metabolically-matched, steady-state treadmill walking at SL (day 7), $5 \mathrm{~h}$ after arriving at $\mathrm{HA}$ (acute HA), and after 22 days of acclimatization and energy deficit (chronic HA, day 42). As previously reported [13] treadmill speed, grade, absolute oxygen uptake (L/ min), and metabolic rate were not different across study phases. All time trials were completed at the same time of day (between 1130 and 1230) and participants were fasted prior to the start of exercise. Participants were given a $5 \mathrm{~min}$ rest after completing the steady-state exercise before performing a self-paced, 2-mile treadmill time trial. Peripheral oxygen saturation $\left(\mathrm{SpO}_{2}\right.$; finger pulse oximetry, Model 9560; Nonin, Plymouth, MN, USA) and heart rate were assessed at baseline and in half mile intervals, and Ratings of Perceived Exertion (RPE) [17] were recorded at baseline and immediately after completing the 2-mile time trial. Participants were familiarized to the test procedures $(80 \mathrm{~min}$ steady-state and 2-mile time trial) on three occasions before completing the SL trial on day 7. The coefficient of variation of the three familiarization time trials was $5.06 \%$, indicating that the test-retest variation in performance was small.

\section{Statistical analyses}

As mentioned, this study was part of a larger investigation [12], powered to test the effects of dietary protein on body composition during altitude acclimatization and concomitant energy deficit. We did not expect dietary protein level to affect time trial performance at chronic HA (neither SL or acute HA were subject to the dietary protein intervention), which we confirmed using linear mixed models with dietary protein level, treatment (CHO, PLA), phase (SL, acute and chronic HA), exercise time point (for $\mathrm{SpO}_{2}$ and heart rate), and their interactions as fixed effects. Therefore, the effects of the dietary protein intervention are not presented in this report, and the data were re-analyzed using the same linear mixed-model without dietary protein in the model. Tukey's HSD tests were used for multiple comparisons if significant main effects of interaction effects were 
observed. Freidman's test was used to assess differences in RPE (baseline, end of the time trial) across study phases. Statistical significance was accepted at $P<0.05$. Data were analyzed using SPSS (v.22.0; Chicago, IL, USA).

\section{Results}

There was no effect $(P>0.05)$ of $\mathrm{CHO}$ on time trial duration, oxygen saturation, heart rate, or RPE across study phases. Time trial duration was longer $(P<0.05)$ at acute HA $(27.3 \pm 6.3 \mathrm{~min})$ compared to chronic HA $(23.6 \pm 4.5$ $\mathrm{min})$ and SL $(17.6 \pm 3.6 \mathrm{~min})$; however, time trial duration at chronic HA was still longer than SL (phase main effect, $P<0.05$, Fig. 1). Mean heart rate and $\mathrm{SpO}_{2}$ during the time trials were lower at acute and chronic HA compared to $\mathrm{SL}$, and $\mathrm{SpO}_{2}$ at chronic $\mathrm{HA}$ was higher than acute HA (phase main effect, $P<0.05$, Table 1 ). RPE was similar across study phases.

\section{Discussion}

This study examined the effects of consuming supplemental carbohydrate on aerobic exercise performance in recreationally-active, healthy, young lowlanders at HA, before and following 22 days of acclimatization while in a constant state of negative energy balance. We demonstrated that consuming supplemental carbohydrate during steady-state exercise had no performance-enhancing effects on time trial performance before or after $\mathrm{HA}$ acclimatization. As expected, time trial performance was approximately 55\% slower at acute HA compared to SL. Acclimatization partially restored exercise performance relative to acute $\mathrm{HA}$; however, time trial performance at chronic HA was still 34\% slower than SL. Carbohydrate supplementation had no effect on perceived effort during any of the performance trials. These data, which were derived from a highly controlled exercise and diet intervention study, suggest that carbohydrate supplementation does not enhance aerobic exercise performance of lowlanders at HA.

In our study, supplemental carbohydrate did not enhance exercise performance in lowlanders acutely exposed to HA (5 h), which conflicts with data reported by Fulco et al. [9], who demonstrated that lowlanders consuming carbohydrate on the third day of continuous residence at $4300 \mathrm{~m}$ performed a $720 \mathrm{~kJ}$ cycle ergometry time trial faster than participants consuming the placebo. We suspect the discrepancy between our data and those by Fulco et al. [9] are due, in part, to the apparent inability to effectively oxidize exogenous carbohydrate upon initial exposure to HA. In the same study, we demonstrated a $52 \%$ reduction in exogenous carbohydrate oxidation and a corresponding increase in endogenous carbohydrate oxidation (i.e., blood glucose, muscle and liver glycogen) during the $80 \mathrm{~min}$ steady-state exercise bout with acute $\mathrm{HA}$ exposure compared to $\mathrm{SL}^{13}$. The mechanisms accounting for the reduction in exogenous carbohydrate oxidation during acute HA exposure are not known, but may be attributable to adjustments in glycemic regulation, as participants were markedly hyperinsulinemic, which inhibited lipolysis and likely accelerated glycogenic flux. The inability to effectively oxidize exogenous carbohydrate during acute HA exposure was alleviated after 22 days of acclimatization [13]. It is possible that the adaptations that improve exogenous carbohydrate oxidation with acclimatization develop within only a few days of HA exposure, which would account for the performance enhancing effects observed by Fulco et al. [9] after 3 days of acclimatization. That, combined with the longer duration time trial (greater reliance on carbohydrates) in the Fulco study [9] (720 kJ cycle ergometry time trial), compared to our 2-mile time trial, may explain why they observed improvements in time trial performance and we did not.

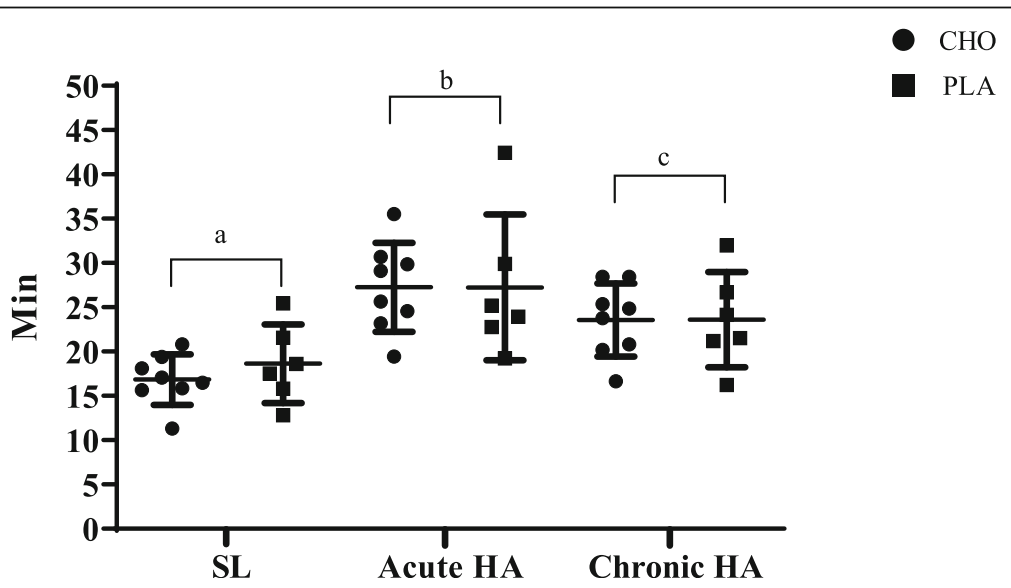

Fig. 1 2-mile time trial duration (min) at sea level, acute and chronic HA for CHO and PLA. Values are presented as mean \pm SD. Points not sharing the same letter are different (phase main effect, P < 0.05). SL, sea level; HA, high altitude; CHO, carbohydrate; PLA, placebo 
Table 1 Heart rate, peripheral oxygen saturation, and ratings of perceived exertion during the 2-mile time trial ${ }^{\mathrm{a}}$

\begin{tabular}{|c|c|c|c|c|c|c|}
\hline & \multicolumn{2}{|l|}{ SL } & \multicolumn{2}{|l|}{ Acute HA } & \multicolumn{2}{|l|}{ Chronic HA } \\
\hline & $\mathrm{CHO}$ & PLA & $\mathrm{CHO}$ & PLA & $\mathrm{CHO}$ & PLA \\
\hline $\mathrm{HR}(\mathrm{bpm})^{2}$ & $181 \pm 10$ & $175 \pm 9$ & $159 \pm 9$ & $168 \pm 14$ & $166 \pm 13$ & $161 \pm 18$ \\
\hline $\mathrm{SpO}_{2}(\%)^{2,3}$ & $93 \pm 2$ & $95 \pm 3$ & $71 \pm 4$ & $73 \pm 4$ & $77 \pm 3$ & $81 \pm 4$ \\
\hline RPE & $17(14-19)$ & $17(16-18)$ & $16(13-20)$ & $18(15-20)$ & $18(14-19)$ & 19 (16-19) \\
\hline
\end{tabular}

${ }^{a}$ Values presented as mean $\pm S D$, except for RPE which is presented as median (range)

${ }^{2}$ Phase main effect; acute and chronic HA different than $\mathrm{SL}, P<0.05$

${ }^{3}$ Phase main effect; chronic HA different than acute $\mathrm{HA}, P<0.05$.

$S L$ Sea level, $H A$ High altitude, $H R$ Heart rate, $\mathrm{CHO}$ Carbohydrate, $P L A$ Placebo, $\mathrm{SpO}_{2}$ Peripheral oxygen saturation, RPE Rating of Perceived Exertion

Our chronic HA results are in line with what has been previously reported about the influence of carbohydrate supplementation on time trial performance after acclimatization $[9,11]$. Although we demonstrated that ability to oxidize exogenous carbohydrates was restored with acclimatization to HA [13], carbohydrate supplementation still did not improve performance. However, exercise performance in both carbohydrate and placebo following 22 days of acclimatization and energy deficit did improve relative to acute $\mathrm{HA}$ as a result of the normal adaptive responses that occur with acclimatization. Since muscle glycogen utilization is related to relative exercise intensity $\left(\% \mathrm{VO}_{2 \text { peak }}\right)[9,11,18]$, it may be that the exercise intensity during the time trials was not high enough to cause decreases in muscle glycogen that would cause the body to rely on exogenous sources of carbohydrate to complete the exercise task.

The practical implications of our findings must be interpreted in the context of certain experimental limitations. For example, it may be that carbohydrate supplementation did not improve performance due to the potential that such high carbohydrate intakes, particularly at altitude, may have reduced gastric emptying and intestinal carbohydrate absorption [19]. However, those measures were not included in our study. Likewise, our applied performance outcomes may have been strengthened if additional mechanistic measures oxygen transport capacity were included. Our design also does not allow us to completely rule out the potential effects of sustained energy deficit on time trial performance after 22 days of acclimatization. However, including fully fed, energy balance control groups was impractical and outside the scope of our study. We also contend that our findings, which show that carbohydrate supplementation failed to enhance performance following 22 days of acclimatization and concomitant energy deficit, are not only consistent with Fulco et al. [9], but are actually strengthened by our experimental design. More specifically, rather than experimentally enforcing energy balance, we assessed the putative performance enhancing effect of supplemental carbohydrate in response to the real world conditions (i.e., negative energy balance) that lowlanders typically experience during prolonged HA sojourns [10]. Most importantly, considering carbohydrate supplementation did not affect performance, and reliance on endogenous carbohydrate to fuel steady-state exercise appears to be higher during acute HA exposure than it is for absolute intensity-matched exercise at sea level [20], provides practical evidence to recommend that individuals planning to sojourn at HA to complete physically demanding work or exercise should prioritize carbohydrate intake at SL to optimize glycogen stores before ascending to HA.

\section{Conclusion}

We conclude that carbohydrate supplementation during steady-state exercise does not enhance exercise performance in lowlanders acutely exposed to hypoxia or sojourning at HA for 22 days.

\section{Abbreviations \\ CHO: Carbohydrate; HA: High altitude; PLA: Placebo; RPE: Rating of Perceived Exertion; SL: Sea level; $\mathrm{SpO}_{2}$ : Oxygen saturation; USARIEM: US Army Research Institute of Environmental Medicine}

\section{Acknowledgements}

We thank the volunteers that participated in the study. We acknowledge our medical oversight team and Dr. Stephen Muza for their support of this study. Importantly, we sincerely thank Mr. Bradley Anderson, Ms. Katelyn Guerriere, Mr. Grant Holmes, Mr. Anthony Karis, Mr. Matthew Kominsky, Ms. Allyson Derosier, Ms. Adrienne Hatch, Ms. Laura Lutz, Mr. Phillip Niro, Ms. Nancy Murphy, Drs. Steven Hennigar, Taylor Roth, Arny Ferrando, J. Phillip Karl, Lee Margolis, Scott Montain, John Carbone, James McClung, and LTC Renee Cole for their significant contributions to the study.

\section{Declarations}

The opinions or assertions contained herein are the private views of the authors and are not to be construed as official or as reflecting the views of the Army or the Department of Defense. Any citations of commercial organizations and trade names in this report do not constitute an official Department of the Army endorsement of approval of the products or services of these organizations.

\section{Authors' contributions}

CEB, RWK, AJY, and SMP designed the research; KEB, CEB, MAW, AJL, RWK, AJY, and SMP performed the research. KEB and AJL analyzed the data. KEB and SMP prepared tables, figures, and drafted the manuscript. All authors edited and revised the manuscript and approved the final version.

\section{Funding}

This work was supported by the US Army Medical Research and Development Command. 


\section{Availability of data and materials}

The datasets used and/or analyzed during the current study are available from the corresponding author on reasonable request.

\section{Ethics approval and consent to participate}

The study was approved by the Institutional Review Board at the US Army Research Institute of Environmental Medicine (USARIEM, Natick, MA) and participants provided written informed consent prior to any participation in the study. The research was performed in accordance with the Declaration of Helsinki.

\section{Consent for publication}

Not applicable.

\section{Competing interests}

The authors declare that they have no competing interests.

\section{Author details}

'Thermal and Mountain Medicine Division, US Army Research Institute of Environmental Medicine, 10 General Greene Avenue, Bldg, Natick, MA 42, USA. ${ }^{2}$ Military Nutrition Division, US Army Research Institute of Environmental Medicine, 10 General Greene Avenue, Bldg, Natick, MA 42, USA. ${ }^{3}$ Oak Ridge Institute for Science and Education, 4962 Millennium Drive, Suite, Belcamp, MD 101, USA.

Received: 9 October 2019 Accepted: 3 January 2020

Published online: 09 January 2020

\section{References}

1. Fulco CS, Rock PB, Cymerman A. Maximal and submaximal exercise performance at altitude. Aviat Space Environ Med. 1998:69:793-801.

2. Grover RF, Weil JV, Reeves JT. Cardiovascular adaptation to exercise at high altitude In Exercise and sport science reviews. New York: Maxmillian; 1986. p. 269-302.

3. Young AJ, Young PM. In: Pandolf KB, Sawka MN, Gonzalez RR, editors. Human acclimatization to high terrestrial altitude In Human performance physiology and environmental medicine at terrestrial extremes. Indianapolis: Benchmark Press; 1988. p. 497-543.

4. Griffiths A, Shannon OM, Matu J, King R, Deighton K, O'Hara JP. The effects of environmental hypoxia on substrate utilisation during exercise: a metaanalysis. J Int Soc Sports Nutr. 2019;16:1-14.

5. Peronnet F, Massicotte D, Folch N, et al. Substrate utilization during prolonged exercise with ingestion of (13)c-glucose in acute hypobaric hypoxia (4,300 m). Eur J Appl Physiol. 2006:97:527-34.

6. Brooks GA, Butterfield GE, Wolfe RR, et al. Increased dependence on blood glucose after acclimatization to 4,300 m. J Appl Physiol (Bethesda, Md : 1985). 1991;70:919-27.

7. Jeukendrup A. A step towards personalized sports nutrition: Carbohydrate intake during exercise. Sports Med (Auckland, NZ). 2014;44 Suppl 1:S25-33.

8. Jeukendrup AE. Carbohydrate intake during exercise and performance. Nutrition (Burbank, Los Angeles County, Calif). 2004;20:669-77.

9. Fulco CS, Kambis KW, Friedlander AL, et al. Carbohydrate supplementation improves time-trial cycle performance during energy deficit at 4,300-m altitude. J Appl Physiol (Bethesda, Md : 1985). 2005;99:867-76.

10. Butterfield GE. Nutrient requirements at high altitude. Clin Sports Med. 1999; 18:607-21 viii.

11. Fulco CS, Zupan M, Muza SR, et al. Carbohydrate supplementation and endurance performance of moderate altitude residents at $4300 \mathrm{~m}$. Int J Sports Med. 2007:28:437-43.

12. Berryman CE, Young AJ, Karl JP, et al. Severe negative energy balance during $21 \mathrm{~d}$ at high altitude decreases fat-free mass regardless of dietary protein intake: a randomized controlled trial. FASEB J. 2018;32:894-905.

13. Young AJ, Berryman CE, Kenefick RW, et al. Altitude acclimatization alleviates the hypoxia-induced suppression of exogenous glucose oxidation during steady-state aerobic exercise. Front Physiol. 2018;9:830.

14. Margolis LM, Carbone JW, Berryman CE, et al. Severe energy deficit at high altitude inhibits skeletal muscle mtorc1-mediated anabolic signaling without increased ubiquitin proteasome activity. FASEB J. 2018; fj201800163RR:5955-66.
15. Karl JP, Berryman CE, Young AJ, et al. Associations between the gut microbiota and host responses to high altitude. Am J Physiol Gastrointest Liver Physiol. 2018;315:G1003-g1015.

16. Karl JP, Cole RE, Berryman CE, et al. Appetite suppression and altered food preferences coincide with changes in appetite-mediating hormones during energy deficit at high altitude, but are not affected by protein intake. High Alt Med Biol. 2018;19:156-69.

17. Borg G. Perceived exertion as an indicator of somatic stress. Scand J Rehabil Med. 1970;2:92-8.

18. Coggan AR, Coyle EF. Carbohydrate ingestion during prolonged exercise: effects on metabolism and performance. Exerc Sport Sci Rev. 1991:19:1-40.

19. Maughan RJ. Fluid and electrolyte loss and replacement in exercise. J Sports Sci. 1991;9 Spec No:117-42

20. Young AJ, Margolis LM, Pasiakos SM. Commentary on the effects of hypoxia on energy substrate use during exercise. J Int Soc Sports Nutr. 2019;16:28.

\section{Publisher's Note}

Springer Nature remains neutral with regard to jurisdictional claims in published maps and institutional affiliations.

Ready to submit your research? Choose BMC and benefit from:

- fast, convenient online submission

- thorough peer review by experienced researchers in your field

- rapid publication on acceptance

- support for research data, including large and complex data types

- gold Open Access which fosters wider collaboration and increased citations

- maximum visibility for your research: over $100 \mathrm{M}$ website views per year

At $\mathrm{BMC}$, research is always in progress.

Learn more biomedcentral.com/submissions 